\title{
Metyrapone Tartrate
}

National Cancer Institute

\section{Source}

National Cancer Institute. Metyrapone Tartrate. NCI Thesaurus. Code C81114.

The tartrate salt form of metyrapone, a pyridine derivative and an inhibitor of steroid 11beta-hydroxylase with anti-adrenal activity. Metyrapone inhibits steroid 11-betahydroxylase, thereby inhibiting the synthesis of cortisol from 11-deoxycortisol, and corticosterone, the precursor of aldosterone, from deoxycorticosterone in the adrenal gland. Removal of the negative feedback mechanism exerted by cortisol results in increased adrenocorticotropic hormone (ACTH) secretion by the pituitary gland. In turn, continued stimulation of the adrenal gland by ACTH results in the accumulation of corticoid precursors, 11-deoxycortisol and deoxycorticosterone. These corticoid precursors are excreted in urine and may be used as indicators for hypothalamic-pituitary ACTH function. 